\title{
Protection of bone in premenopausal women with breast cancer: focus on zoledronic acid
}

\author{
This article was published in the following Dove Press journal: \\ International Journal of Women's Health \\ 17 October 2012 \\ Number of times this article has been viewed
}

\section{Rebecca Aft \\ Department of Surgery, Washington University School of Medicine, St Louis, MO, USA}

\begin{abstract}
Maintaining bone health is important for patients with breast cancer (BC), the most commonly diagnosed cancer in American women. Indeed, bone loss is common throughout the $\mathrm{BC}$ disease continuum. In the metastatic BC setting, patients are likely to develop bone metastases, a painful complication that can lead to potentially debilitating skeletal-related events. Bone health is equally important for patients with early BC. During adjuvant therapy for early $\mathrm{BC}$, the largest challenge to bone health is from accelerated bone mineral density (BMD) loss. Although decreased BMD is well recognized in older, postmenopausal women, it may be underestimated in younger, premenopausal women undergoing endocrine therapy for BC. The rate and extent of cancer therapy-induced bone loss (from chemotherapy or endocrine therapy) are substantially greater than normal decreases in BMD during menopause. Bisphosphonates such as zoledronic acid (ZOL) are antiresorptive agents indicated for the treatment of bone metastases from BC. Clinical trials over the past few years suggest that, although not yet approved for this indication, ZOL can prevent cancer therapy-induced bone loss and improve BMD in premenopausal women receiving adjuvant (endocrine or chemo-) therapy for BC. Furthermore, the benefits of ZOL therapy may go beyond maintaining bone health and include potential anticancer benefits together with favorable tolerability and cost/ benefit profiles. This review will focus specifically on the role of ZOL in preserving the bone health of premenopausal women with BC.
\end{abstract}

Keywords: breast cancer, premenopausal, zoledronic acid

\section{Introduction}

Breast cancer (BC) is the most commonly diagnosed cancer among American women. ${ }^{1}$ Indeed, in 2010 it was estimated that in the USA 207,090 women were diagnosed with $\mathrm{BC}$ and 39,840 women died from the disease. ${ }^{1}$ Following surgical resection of the tumor, patients with $\mathrm{BC}$ receive adjuvant therapy, which includes chemotherapy (eg, taxanes, anthracyclines, cyclophosphamide-methotrexate-fluorouracil) and hormonal therapy. Challenges to bone health common in patients with $\mathrm{BC}$ include bone metastases in advanced disease and bone loss due to adjuvant therapies (endocrine suppression and chemotherapy) in early disease.

\section{Bone disease in advanced BC}

Bone metastases develop in $65 \%$ to $75 \%$ of patients with advanced $\mathrm{BC},{ }^{2,3}$ regardless of menopausal status. Interactions between BC cells and cells that regulate bone metabolism result in a vicious cycle leading to increased cancer growth and spread of bone metastases and bone loss. ${ }^{3}$ Metastatic bone disease in $\mathrm{BC}$ is a painful complication 
characterized by elevated rates of localized osteolysis, which can lead to potentially debilitating skeletal-related events (SREs). ${ }^{3}$ All SREs (ie, pathologic fracture, spinal cord compression, radiotherapy to bone, hypercalcemia of malignancy, and surgery to bone) are associated with decreased quality of life, but pathologic fractures are also associated with decreased survival. ${ }^{4,5}$

\section{Bone disease in early BC}

Adjuvant therapy for early BC causes accelerated bone mineral density (BMD) loss, especially in premenopausal patients. Bone is maintained through a continuous remodeling process involving resorption of existing bone by osteoclasts and formation of new bone by osteoblasts. Estrogen and normal estrogen receptor function help maintain this coupled and balanced process. Decreased estrogen levels due to natural menopause or artificial menopause, caused by chemotherapy-induced ovarian failure or ovarian suppression, are detrimental to bone health as reduced estrogen levels can lead to bone loss. ${ }^{6}$

Ovarian suppression or selective estrogen receptor modulators are used to treat premenopausal women with hormone-receptor-positive BC. ${ }^{7}$ Ovarian ablation causes immediate, artificial menopause, and chemotherapy can lead to ovarian failure. Subsequently, estrogen levels decrease dramatically, resulting in increased osteoclast-mediated bone resorption and subsequent BMD decrease. ${ }^{8-10}$ Tamoxifen, although bone-sparing in postmenopausal women or when used concurrently with ovarian suppression, is associated with bone loss when used as monotherapy in premenopausal patients. ${ }^{11}$ Although decreased BMD is well recognized in older, postmenopausal women, it may be underestimated in younger, premenopausal women receiving adjuvant therapy for $\mathrm{BC}$. The rate and extent of cancer therapy-induced bone loss (CTIBL) are more than twofold greater than normal decreases in BMD during menopause, suggesting that traditional antiosteoporosis doses of bisphosphonates (BPs) might be insufficient to counter CTIBL. ${ }^{9,10,12}$

Antiresorptive therapies are used to prevent CTIBL associated with adjuvant BC therapy. Nitrogen-containing bisphosphonates (N-BPs) such as zoledronic acid (ZOL) and pamidronate are indicated for the treatment of bone metastases from BC. ${ }^{13,14}$ Numerous clinical studies have demonstrated that, in addition to their established roles in the metastatic setting, BPs can preserve BMD in patients receiving adjuvant therapy for $\mathrm{BC} . .^{9,10,15-20}$ This review will focus specifically on the role of ZOL in preserving the bone health of premenopausal women with BC.

\section{Zoledronic acid mechanisms of action}

All BPs are antiresorptive, bone-targeted agents that induce apoptosis in osteoclasts. Non-nitrogen-containing BPs (ie, clodronate) are metabolized into nonhydrolyzable, cytotoxic analogues of adenosine triphosphate. ${ }^{21}$ In contrast, N-BPs (eg, ibandronate, pamidronate, ZOL) inhibit farnesyl diphosphate (FPP) synthase, a key enzyme in the mevalonate pathway. This important biochemical pathway is involved in the production of cholesterol and isoprenoids, which are required for maintaining cell membrane integrity, producing steroids, and regulating cellular respiration. ${ }^{22}$ Inhibition of FPP synthase leads to impaired prenylation and subcellular localization of G-proteins, consequently reducing the function of Ras family proteins (small signaling molecules involved in a range of cellular functions). ${ }^{23,24}$ Furthermore, FPP synthase inhibition also impedes signal transduction and triggers osteoclast apoptosis. ${ }^{25,26}$ In preclinical studies, ZOL was the most potent FPP synthase inhibitor among N-BPs evaluated and also demonstrated the greatest antiresorptive activity. ${ }^{23}$

\section{Preserving bone health Advanced BC}

Antiresorptive agents such as BPs and denosumab reduce the risk of skeletal complications in patients with metastatic $\mathrm{BC}$, regardless of menopausal or hormone receptor status. ${ }^{27,28}$ Pamidronate and ZOL are well-established BPs with long-term tolerability and efficacy profiles (first approved by the United States Food and Drug Administration in 1991 and 2001, respectively). ${ }^{13,14,29}$ Pamidronate and ZOL are indicated for the treatment of malignant bone disease in patients with $\mathrm{BC}$ or multiple myeloma. ${ }^{13,14}$ However, ZOL is also indicated for the treatment of bone metastases from prostate cancer and other solid tumors, in addition to $\mathrm{BC} .{ }^{13}$ Denosumab, a monoclonal antibody against the receptor activator of nuclear factor- $\mathrm{KB}$ ligand, is a newer antiresorptive agent also indicated for the treatment of bone metastases from solid tumors, including $\mathrm{BC}$ but not multiple myeloma ${ }^{27}$ Several clinical trials have demonstrated the efficacy of antiresorptive agents (BPs and denosumab) for delaying the onset of SREs in patients with advanced BC. ${ }^{28,30,31}$ Accordingly, the American Society of Clinical Oncology and the National Comprehensive Cancer Network have specifically updated their guidelines to recommend ZOL, pamidronate, and denosumab for patients with advanced BC. ${ }^{32,33}$

\section{Early BC}

Antiresorptive agents preserve BMD by blocking bone resorption by osteoclasts. Although BPs are not indicated 
in the United States for the prevention of CTIBL in patients with BC, a number of studies have shown that these agents are effective for maintaining BMD during adjuvant therapy for BC in premenopausal women (Table 1).9,10,17-20,34 Thus far, the effects of denosumab on BMD have not been studied specifically in premenopausal women with BC, although it has been shown to be effective in preventing bone loss in postmenopausal women with osteoporosis or receiving aromatase inhibitors for early BC. ${ }^{35,36}$ Similarly, ZOL has also demonstrated efficacy for preventing bone loss in these patient populations. ${ }^{37-40}$ However, several studies also have shown ZOL to be effective for preserving or improving BMD in premenopausal women with early BC.

For example, in one trial with premenopausal women receiving adjuvant chemotherapy for early stage $\mathrm{BC}, 101$ patients were randomized to receive intravenous (IV) ZOL (4 mg every 3 months) or placebo. ${ }^{17}$ At 12 months, patients who received ZOL had stable BMD while those who received placebo experienced BMD loss at the lumbar spine (-4.1\%) and total hip $(-2.6 \% ; P<0.0001) .{ }^{17}$ Furthermore, this benefit with ZOL was maintained 1 year after completion of ZOL treatment. Patients who received placebo continued to experience declining BMD at the lumbar spine $(-6.3 \%)$ and total hip $(-2.6 \%)$ through 24 months, compared with stable BMD at both sites in patients who received ZOL $(P<0.0001) .{ }^{18}$

The Cancer and Leukemia Group B 79809 trial is another study that examined the effects of ZOL on CTIBL from chemotherapy-induced ovarian failure in premenopausal women. In this study, premenopausal women with stage 1-3 $\mathrm{BC}(\mathrm{n}=439)$ were randomized to receive ZOL (IV $4 \mathrm{mg}$ every 3 months for 2 years) either early (within 3 months of randomization) or late (1 year after randomization). ${ }^{10}$ In patients with baseline and 1-year BMD measurements $(\mathrm{n}=302)$, early ZOL treatment (ie, started with chemotherapy) prevented CTIBL and significantly increased BMD above baseline levels $(+1.4 \%)$ compared with no ZOL $(-5.5 \% ; P<0.001) .{ }^{10}$ Although tamoxifen therapy was associated with more modest BMD loss than chemotherapy alone in patients who did not receive ZOL, CTIBL was not completely attenuated. In a subset of women who developed

Table I Trials of bisphosphonates for prevention of bone loss in premenopausal women receiving adjuvant endocrine therapy for breast cancer

\begin{tabular}{|c|c|c|c|}
\hline Bisphosphonate & $\mathbf{N}$ & Dose & Results \\
\hline PAM $^{16}$ & 40 & 60 mg IV Q3M for 9 mo & $\begin{array}{l}\text { Preserved baseline BMD at I-y follow-up } \\
\downarrow \text { LS bone loss vs placebo at I y }(P=0.002)\end{array}$ \\
\hline $\mathrm{CLO}^{67}$ & 73 & 1600 mg/day PO for 3 y & $\begin{array}{l}\text { Preserved baseline BMD at } 3 \text {-y follow-up } \\
\downarrow \text { LS bone loss vs placebo at } 5 \text { y }(P=0.008)\end{array}$ \\
\hline $\mathrm{CLO}^{34}$ & 148 & 1600 mg/day PO for 2 y & $\begin{array}{l}\downarrow L S \text { bone loss vs no } C L O \text { at } 2 y \\
(-2.2 \% \text { vs }-5.9 \% ; P=0.0005) \\
\text { Preserved BMD at FN vs no CLO at } 2 \text { y } \\
(+0.9 \% \text { vs }-2.0 \% ; P=0.017)\end{array}$ \\
\hline $\mathrm{CLO}^{20}$ & 311 & 1600 mg/day PO for 2 y & $\begin{array}{l}\uparrow \text { BMD at the } \mathrm{LS} \text { and } \mathrm{TH} \text { vs placebo at } \mathrm{I} y \\
(2.38 \% \text { and } 0.74 \% \text {, respectively) and } 2 \mathrm{y} \\
(\mathrm{I} .72 \% \text { and } I .85 \% \text {, respectively) }\end{array}$ \\
\hline $\mathrm{RIS}^{15}$ & 53 & $\begin{array}{l}8 \times 12 \text {-wk cycles } \\
(30 \mathrm{mg} / \text { day } \times 2 \text { wk and no treatment } \times 10 \mathrm{wk})\end{array}$ & $\begin{array}{l}\text { Preserved baseline LS BMD at } 2-y \text { follow-up } \\
(-0.2 \% \text { vs }-2.5 \%)\end{array}$ \\
\hline $\mathrm{RIS}^{41}$ & 216 & $35 \mathrm{mg} / \mathrm{wk} \mathrm{PO}$ & $\begin{array}{l}\text { Failed to prevent CTIBL at I-y follow-up } \\
\text { for RIS vs placebo } \\
\text { ( } n=170 ;-4.3 \% \text { vs }-5.4 \%)\end{array}$ \\
\hline $\mathrm{ZOL}^{17,18}$ & 101 & $4 \mathrm{mg}$ IV Q3M for $12 \mathrm{mo}$ & $\begin{array}{l}\text { Preserved baseline BMD vs placebo } \\
(P<0.000 \mathrm{I} ; \text { LS BMD }-5.5 \% \text { at } 12 \mathrm{mo} \\
\text { and }-6.3 \% \text { at } 24 \mathrm{mo} \text { with placebo })\end{array}$ \\
\hline $\mathrm{ZOL}^{19}$ & 112 & 4 mg IV Q6M for I y & $\begin{array}{l}\downarrow \text { bone loss vs no ZOL at I y }(-1.1 \% \text { vs }-7.5 \% \text {; } \\
P<0.00 \text { I) }\end{array}$ \\
\hline $\mathrm{ZOL}^{9}$ & 404 & 4 mg IV Q6M for 3 y & $\begin{array}{l}\uparrow \text { LS BMD vs baseline at } 3 \text { y }(+0.4 \%) \text { and } 5 \text { y } \\
(+4.0 \% ; P=0.02) \\
\text { No ZOL } \downarrow \text { LS BMD vs baseline at } 3 \text { y } \\
(-11.3 \% ; P<0.000 I) \text { and } 5 \text { y }(-6.3 \% ; P=0.00 I)\end{array}$ \\
\hline $\mathrm{ZOL}^{10}$ & 439 & $4 \mathrm{mg}$ IV Q3M for 2 y & $\begin{array}{l}\uparrow \text { BMD vs placebo at I y } \\
(+I .2 \% \text { vs }-6.7 \% \text {, respectively; } P<0.00 \text { I })\end{array}$ \\
\hline
\end{tabular}

Abbreviations: BMD, bone mineral density; CLO, clodronate; CTIBL, cancer therapy induced bone loss; FN, femoral neck; IV, intravenous; LS, lumbar spine; mo, months; N, number; P, probability level; PAM, pamidronate; PO, oral; Q3M, every 3 months; Q6M, every 6 months; RIS, risedronate; TH, total hip; vs, versus; wk, weeks; ZOL, zoledronic acid; $y$, years; $\uparrow$, indicates increase; $\downarrow$, indicates decrease. 
chemotherapy-induced ovarian failure at 1 year $(n=150)$, early ZOL treatment prevented CTIBL and significantly increased BMD above baseline levels $(+1.2 \%)$ compared with no ZOL therapy $(-6.7 \% ; P<0.001) .{ }^{10}$ At 3 years, 1 year after completion of 2 years of $Z O L$ therapy, patients who received early ZOL maintained increased BMD (+1.0\%) versus baseline, compared with those who received late ZOL (1 year of no ZOL followed by 1 year of ZOL, $-0.5 \% ; P=0.019$ ). Notably, ZOL improved BMD in this patient population regardless of concomitant tamoxifen therapy.

A bone substudy of the Austrian Breast and Colorectal Cancer Study Group trial 12 (ABCSG-12) examined the effects of $\mathrm{ZOL}$ on $\mathrm{BMD}$ in premenopausal women receiving adjuvant endocrine therapy (ovarian blockade with goserelin plus tamoxifen or anastrozole) for BC. In this substudy, premenopausal women $(n=404)$ receiving ZOL (IV 4 mg every 6 months for 3 years) plus endocrine therapy had stable BMD during treatment $(P=0.02)$ and a substantial improvement in BMD $(+0.4 \%) 2$ years after therapy completion. ${ }^{9}$ In contrast, BMD decreased during treatment in patients receiving endocrine therapy alone (lumbar spine, $-11.3 \% ; P<0.0001$ ) and remained below baseline 2 years after completion of therapy. Therefore, ZOL prevented bone loss during adjuvant endocrine therapy and improved BMD at 5 years, 2 years after completion of both endocrine and ZOL treatment.

Together, these studies demonstrate that, although not yet approved for this indication, ZOL prevents CTIBL and improves BMD in premenopausal women receiving adjuvant (endocrine or chemo-) therapy for BC and supports reevaluation of treatment paradigms to potentially include ZOL in this patient population. In contrast, there is little evidence to support the use of oral BPs in this setting. For example, weekly risedronate $(35 \mathrm{mg}$ ) did not prevent bone loss compared with placebo in premenopausal women undergoing chemotherapy for BC $(n=216) .{ }^{41}$ In addition to CTIBL prevention, emerging data suggest potential benefits with $\mathrm{ZOL}$ therapy that go beyond prevention of bone loss and include potential anticancer benefits and favorable tolerability and cost-benefit profiles. ${ }^{42-48}$

\section{Additional considerations for choice of BP: anticancer benefit, safety, and cost}

In addition to the prevention of CTIBL, several other factors influence the choice of antiresorptive therapy in premenopausal women with BC. Of particular interest are potential anticancer benefits associated with BPs and treatment safety and costs for all antiresorptive therapies. Each of these factors may influence patient and physician preference for a given antiresorptive therapy.

\section{Anticancer benefit and potential mechanism}

The primary objective of the ABCSG-12 study was to evaluate the effect of ZOL on disease-free survival (DFS) in premenopausal women receiving adjuvant endocrine therapy for early BC. Women with stage 1-2 hormone-receptor-positive $\mathrm{BC}(\mathrm{n}=1803)$ were randomized to receive endocrine therapy (goserelin plus tamoxifen or anastrozole) alone or endocrine therapy in combination with ZOL (IV 4 mg every 6 months) for 3 years. ${ }^{49}$ The initial study report at a median follow-up of 48 months showed that the addition of ZOL to adjuvant endocrine therapy significantly improved DFS by $36 \%$ (hazard ratio $[\mathrm{HR}]=0.64 ; P=0.01) .{ }^{49}$ This effect was maintained through the 84-month median follow-up 4 years after therapy completion, with DFS improved by $28 \%$ with ZOL (HR $=0.72 ; P=0.014$ ) compared with endocrine therapy alone. Furthermore, at the 84-month median follow-up, ZOL demonstrated improved overall survival compared with no ZOL $(\mathrm{HR}=0.63 ; P=0.049) .{ }^{50}$ These data suggest a sustained anticancer effect that lasts well beyond the end of therapy.

The observed anticancer activity of ZOL may be mediated through its effects on the bone microenvironment and the role of this environment in BC progression. Cells from the primary tumor released into circulation (circulating tumor cells, CTCs) may recolonize their tissues of origin (local relapse) or may invade bone or visceral organs (distant relapse). Some of these CTCs colonize the bone marrow and are subsequently referred to as disseminated tumor cells (DTCs). Notably, BC CTCs preferentially colonize the bone marrow because this microenvironment supports cancer cell survival and growth, ${ }^{51,52}$ and $\mathrm{BC}$ cells in bone may secrete factors that can increase rates of bone resorption. ${ }^{3,53}$ Influencing the bone microenvironment with ZOL also may reduce the availability of bone-derived growth factors and thus contribute to reduced disease recurrences in extraskeletal sites. Indeed, clinical data suggest that ZOL reduces the persistence and prevalence of DTCs in the bone marrow of patients with BC. ${ }^{54-57}$ This is clinically relevant, as DTCs in the bone marrow may be a source of subsequent local and distant relapse; therefore, reducing DTC persistence may improve survival. ${ }^{53,58}$

The effects of ZOL on CTCs combined with the results of ABCSG-12 suggest that ZOL may prevent increased osteolysis and alter the bone microenvironment to make it less conducive for colonization and proliferation of cancer cells. However, further study is needed to fully delineate 
the patient population that could benefit most from ZOL therapy. For example, the Adjuvant Zoledronic Acid to Reduce Recurrence (AZURE) trial did not show clinical benefit (DFS improvement) with ZOL (HR $=0.98 ; P=0.79)$ in the overall study population $(\mathrm{n}=3360$, pre- and postmenopausal women receiving standard adjuvant systemic anticancer therapy alone or in combination with ZOL). ${ }^{59}$ However, standard therapy decisions were at the treating physician's discretion. Based on standard practices in the United Kingdom during the study, premenopausal women with early BC ( $n=1503$ in AZURE) were unlikely to undergo estrogen suppression (as in ABCSG-12), thereby resulting in substantial heterogeneity in endocrine hormone levels in these patients. Notably, ZOL significantly improved invasive DFS $(\mathrm{HR}=0.75 ; P=0.02)$ and overall survival $(\mathrm{HR}=0.74$; $P=0.04)$ in the postmenopausal subset $(\mathrm{n}=1041)$ in AZURE, suggesting that the endocrine environment is key to realizing DFS benefits with ZOL therapy ${ }^{59}$ Intriguingly, subset analyses from ABCSG-12 showed that patients $>40$ years of age experienced significant DFS benefits with ZOL $(\mathrm{n}=1390$; HR $=0.66 ; P=0.013)$, but patients $\leq 40$ years of age did not $(\mathrm{n}=413 ; \mathrm{HR}=0.87 ; P=0.525) .{ }^{50}$ This further supports the observation from AZURE because ovarian suppression is more complete in older than in younger premenopausal women.$^{42}$ Therefore, the potential anticancer activity of ZOL may also require a low estrogen environment.

\section{Safety}

Another advantage of BPs in general and of ZOL in particular is that these agents have a well-defined safety profile, and adverse events are typically manageable. Flu-like symptoms called acute-phase reactions are the most common adverse events associated with N-BPs. However, these reactions generally diminish with subsequent dosing and can be managed with analgesics. ${ }^{13}$ Renal safety is important for patients with cancer receiving ZOL. Because ZOL is cleared through the kidneys, renal function should be monitored by measuring serum creatinine before each dose. ${ }^{13}$ However, renal failure has not been reported in clinical trials of ZOL in premenopausal women with early BC, ${ }^{60}$ possibly due to fewer comorbidities influencing renal function in this patient population compared with older, postmenopausal women with BC.

Osteonecrosis of the jaw (ONJ) is another important safety consideration for patients with BC. Indeed, ONJ is an uncommon but potentially serious adverse event of unknown etiology affecting $1 \%$ to $2 \%$ of patients with advanced $\mathrm{BC}$ receiving complex treatment regimens, including chemotherapy and antiresorptive therapy (ie, BPs or denosumab). ${ }^{31,61}$ However, the risk of ONJ in advanced $\mathrm{BC}$ can be minimized by preventive dental care before the initiation of N-BP therapy, ${ }^{62}$ and conservative management can lead to its resolution. ${ }^{63}$ Furthermore, ONJ is rare in the adjuvant setting, ${ }^{60,64}$ and no cases of ONJ have been reported in premenopausal women with early $\mathrm{BC}$ in ABCSG-12 $(\mathrm{n}=1803) .{ }^{60}$

\section{Cost}

Costs associated with fractures and antiresorptive agents are also important considerations when determining the use of these therapies. Indeed, bone fractures in patients with BC (advanced or early) are associated with increased health care costs. ${ }^{65,66}$ However, ZOL has been shown to be a costeffective treatment option in both the advanced and early BC settings for preventing SREs and bone loss and subsequent fractures due to bone metastases or CTIBL. ${ }^{43,45,47}$

Analyses based on ABCSG-12 show that treatment with $\mathrm{ZOL}$ in combination with endocrine therapy in premenopausal women with early $\mathrm{BC}$ is cost-effective. ${ }^{43}$ Analyses based on the assumption that observed DFS benefits with ZOL continued beyond the 7-year median follow-up of ABCSG-12 showed that the additional costs of ZOL therapy were offset by savings in the costs associated with $\mathrm{BC}$ recurrences. Notably, these analyses showed that ZOL reduced costs by $\$$ US2127 per patient and increased quality-adjusted life-years (QALYs) by 1.63 years. ${ }^{43}$ Moreover, in analyses based on the assumption that DFS benefits with ZOL persist only for the duration of ABCSG-12, the additional costs of ZOL were partially offset by savings in the costs associated with $\mathrm{BC}$ disease recurrences. ${ }^{43}$ Importantly, the costeffectiveness of adding ZOL to endocrine therapy versus endocrine therapy alone ( $<\$$ US10,000 per QALY gained) was substantially below the threshold generally considered favorable in the USA (ie, \$US50,000 per QALY gained), and less than that of other generally accepted oncology therapies. These analyses show that ZOL is a cost-effective therapy primarily because of improvements in survival and reduced risk of disease recurrence. ${ }^{43}$

\section{Conclusions}

Bone health is an important consideration for patients with $\mathrm{BC}$ in both the adjuvant and metastatic settings. Bone loss occurs throughout the $\mathrm{BC}$ disease continuum and can result in bone-related complications that compromise quality of life and treatment adherence with primary anticancer therapy. Antiresorptive therapies are critical for preserving bone health in all women with $\mathrm{BC}$. To date, ZOL has been 
examined extensively in pre- and postmenopausal women with BC. As with pamidronate and denosumab, ZOL has been shown to delay the onset of SREs in patients with bone metastases from BC. However, other BPs might be less effective and, in contrast to the large data pool available for $\mathrm{ZOL}$, denosumab has yet to be evaluated in the adjuvant CTIBL setting in premenopausal women with BC. In combination with primary anticancer therapy, ZOL may improve cancerrelated outcomes in some patient populations. Evidence to date suggests that ZOL can effectively preserve BMD in premenopausal women receiving endocrine therapy for $\mathrm{BC}$ and may provide additional anticancer benefits (especially in patients undergoing ovarian suppression). Furthermore, ZOL has a well-established safety profile and is a cost-effective therapy. Overall, the clinical and economic data support the use of ZOL in women with BC.

\section{Acknowledgments}

Financial support for medical editorial assistance was provided by Novartis Pharmaceuticals Corporation. We thank Duprane Pedaci Young, ProEd Communications, Inc, for her medical editorial assistance with this manuscript.

\section{Disclosure}

Dr Aft has worked as a consultant for and received honoraria from Novartis.

\section{References}

1. Jemal A, Siegel R, Xu J, Ward E. Cancer statistics, 2010. CA Cancer J Clin. 2010;60(5):277-300.

2. Coleman RE. Skeletal complications of malignancy. Cancer. 1997; 80(8 Suppl):1588-1594.

3. Mundy GR. Metastasis to bone: causes, consequences and therapeutic opportunities. Nat Rev Cancer. 2002;2(8):584-593.

4. Saad F. New research findings on zoledronic acid: survival, pain, and anti-tumour effects. Cancer Treat Rev. 2008;34(2):183-192.

5. Weinfurt KP, Li Y, Castel LD, et al. The significance of skeletal-related events for the health-related quality of life of patients with metastatic prostate cancer. Ann Oncol. 2005;16(4):579-584.

6. National Osteoporosis Foundation. Clinician's Guide to Prevention and Treatment of Osteoporosis. Washington, DC: National Osteoporosis Foundation; 2010. Available from: http://www.nof.org. Accessed 4 April 2012.

7. Early Breast Cancer Trialists' Collaborative Group (EBCTCG). Effects of chemotherapy and hormonal therapy for early breast cancer on recurrence and 15-year survival: an overview of the randomised trials. Lancet. 2005;365(9472):1687-1717.

8. Eastell R, Adams JE, Coleman RE, et al. Effect of anastrozole on bone mineral density: 5-year results from the anastrozole, tamoxifen, alone or in combination trial 18233230. J Clin Oncol. 2008;26(7):1051-1057.

9. Gnant M, Mlineritsch B, Luschin-Ebengreuth G, et al; for Austrian Breast and Colorectal Cancer Study Group (ABSCG). Adjuvant endocrine therapy plus zoledronic acid in premenopausal women with early-stage breast cancer: 5-year follow-up of the ABCSG-12 bone-mineral density substudy. Lancet Oncol. 2008;9(9):840-849.
10. Shapiro CL, Halabi S, Hars V, et al. Zoledronic acid preserves bone mineral density in premenopausal women who develop ovarian failure due to adjuvant chemotherapy: final results from CALGB trial 79809. Eur J Cancer. 2011;47(5):683-689.

11. Vehmanen L, Elomaa I, Blomqvist C, Saarto T. Tamoxifen treatment after adjuvant chemotherapy has opposite effects on bone mineral density in premenopausal patients depending on menstrual status. J Clin Oncol. 2006;24(4):675-680.

12. Hadji P. Aromatase inhibitor-associated bone loss in breast cancer patients is distinct from postmenopausal osteoporosis. Crit Rev Oncol Hematol. 2009;69(1):73-82.

13. Zometa ${ }^{\circledR}$ (zoledronic acid) [package insert]. East Hanover, NJ: Novartis Pharmaceuticals Corporation; 2011.

14. Aredia $^{\circledR}$ (pamidronate) injection [package insert]. East Hanover, NJ: Novartis Pharmaceuticals Corporation; 2008.

15. Delmas PD, Balena R, Confravreux E, Hardouin C, Hardy P, Bremond A. Bisphosphonate risedronate prevents bone loss in women with artificial menopause due to chemotherapy of breast cancer: a double-blind, placebo-controlled study. J Clin Oncol. 1997;15(3):955-962.

16. Fuleihan GE, Salamoun M, Mourad YA, et al. Pamidronate in the prevention of chemotherapy-induced bone loss in premenopausal women with breast cancer: a randomized controlled trial. J Clin Endocrinol Metab. 2005;90(6):3209-3214.

17. Hershman DL, McMahon DJ, Crew KD, et al. Zoledronic acid prevents bone loss in premenopausal women undergoing adjuvant chemotherapy for early-stage breast cancer. J Clin Oncol. 2008;26(29): 4739-4745.

18. Hershman DL, McMahon DJ, Crew KD, et al. Prevention of bone loss by zoledronic acid in premenopausal women undergoing adjuvant chemotherapy persist up to one year following discontinuing treatment. J Clin Endocrinol Metab. 2010;95(2):559-566.

19. Kim JE, Ahn JH, Jung KH, et al. Zoledronic acid prevents bone loss in premenopausal women with early breast cancer undergoing adjuvant chemotherapy: a phase III trial of the Korean Cancer Study Group (KCSG-BR06-01). Breast Cancer Res Treat. 2011;125(1):99-106.

20. Powles TJ, McCloskey E, Paterson AH, et al. Oral clodronate and reduction in loss of bone mineral density in women with operable primary breast cancer. J Natl Cancer Inst. 1998;90(9):704-708.

21. Frith JC, Monkkonen J, Blackburn GM, Russell RG, Rogers MJ. Clodronate and liposome-encapsulated clodronate are metabolized to a toxic ATP analog, adenosine 5'-(beta, gamma-dichloromethylene) triphosphate, by mammalian cells in vitro. J Bone Miner Res. 1997;12(9): 1358-1367.

22. Fritz G. Targeting the mevalonate pathway for improved anticancer therapy. Curr Cancer Drug Targets. 2009;9(5):626-638.

23. Kavanagh KL, Guo K, Dunford JE, et al. The molecular mechanism of nitrogen-containing bisphosphonates as antiosteoporosis drugs. Proc Natl Acad Sci U S A. 2006;103(20):7829-7834.

24. Russell RG. Bisphosphonates: mode of action and pharmacology. Pediatrics. 2007;119(Suppl 2):S150-S162.

25. Luckman SP, Hughes DE, Coxon FP, Graham R, Russell G, Rogers MJ. Nitrogen-containing bisphosphonates inhibit the mevalonate pathway and prevent post-translational prenylation of GTP-binding proteins, including Ras. J Bone Miner Res. 1998;13(4):581-589.

26. Monkkonen H, Auriola S, Lehenkari P, et al. A new endogenous ATP analog (ApppI) inhibits the mitochondrial adenine nucleotide translocase (ANT) and is responsible for the apoptosis induced by nitrogen-containing bisphosphonates. Br J Pharmacol. 2006;147(4): 437-445.

27. Xgeva ${ }^{\circledR}$ (denosumab) [package insert]. Thousand Oaks, CA: Amgen Inc; 2010.

28. Pavlakis N, Schmidt R, Stockler M. Bisphosphonates for breast cancer. Cochrane Database Syst Rev. 2005;3:CD003474.

29. Food and Drug Administration Center for Drug Evaluation and Research. Oncologic Drugs Advisory Committee Meeting: March 4, 2005. Aredia/Zometa. Available from: www.fda.gov. Accessed 4 April 2012 . 
30. Rosen LS, Gordon D, Kaminski M, et al. Long-term efficacy and safety of zoledronic acid compared with pamidronate disodium in the treatment of skeletal complications in patients with advanced multiple myeloma or breast carcinoma: a randomized, double-blind, multicenter, comparative trial. Cancer. 2003;98(8):1735-1744.

31. Stopeck AT, Lipton A, Body JJ, et al. Denosumab compared with zoledronic acid for the treatment of bone metastases in patients with advanced breast cancer: a randomized, double-blind study. J Clin Oncol. 2010;28(35):5132-5139.

32. Van Poznak CH, Temin S, Yee GC, et al. American Society of Clinical Oncology executive summary of the clinical practice guideline update on the role of bone-modifying agents in metastatic breast cancer. J Clin Oncol. 2011;29(9):1221-1227.

33. National Comprehensive Cancer Network. NCCN Clinical Practice Guidelines in Oncology (NCCN Guidelines) ${ }^{\circledR}$ Breast Cancer. Version 1. 2012.

34. Saarto T, Blomqvist C, Valimaki M, Makela P, Sarna S, Elomaa I. Chemical castration induced by adjuvant cyclophosphamide, methotrexate, and fluorouracil chemotherapy causes rapid bone loss that is reduced by clodronate: a randomized study in premenopausal breast cancer patients. J Clin Oncol. 1997;15(4):1341-1347.

35. Cummings SR, San Martin J, McClung MR, et al. Denosumab for prevention of fractures in postmenopausal women with osteoporosis. N Engl J Med. 2009;361(8):756-765.

36. Ellis GK, Bone HG, Chlebowski R, et al. Randomized trial of denosumab in patients receiving adjuvant aromatase inhibitors for nonmetastatic breast cancer. J Clin Oncol. 2008;26(30):4875-4882.

37. Black DM, Delmas PD, Eastell R, et al; for HORIZON Pivotal Fracture Trial. Once-yearly zoledronic acid for treatment of postmenopausal osteoporosis. N Engl J Med. 2007;356(18):1809-1822.

38. BrufskyAM, HarkerWG, BeckJT, etal. Final 5-year results ofZ-FAST trial: adjuvant zoledronic acid maintains bone mass in postmenopausal breast cancer patients receiving letrozole. Cancer. 2012;118(5):1192-1201.

39. Eidtmann H, de Boer R, Bundred N, et al. Efficacy of zoledronic acid in postmenopausal women with early breast cancer receiving adjuvant letrozole: 36-month results of the ZO-FAST Study. Ann Oncol. 2010;21(11):2188-2194

40. Llombart A, Frassoldati A, Paija O, et al. Immediate administration of zoledronic acid reduces aromatase inhibitor-associated bone loss in postmenopausal women with early breast cancer: 12-month analysis of the E-ZO-FAST trial. Clin Breast Cancer. 2012;12(1):40-48.

41. Hines SL, Mincey BA, Sloan JA, et al. Phase III randomized, placebocontrolled, double-blind trial of risedronate for the prevention of bone loss in premenopausal women undergoing chemotherapy for primary breast cancer. J Clin Oncol. 2009;27(7):1047-1053.

42. Gnant M. Zoledronic acid in the treatment of early-stage breast cancer: is there a final verdict? Curr Oncol Rep. 2012;14(1):35-43.

43. Gnant MF, Kaura S, Sofrygin O, Delea TE. Cost-effectiveness of zoledronic acid plus endocrine therapy in premenopausal women with early stage breast cancer (BC) enrolled in the ABCSG-12 study [poster]. Presented at: IMPAKT-Breast Cancer Conference; May 7-9, 2009; Brussels, Belgium. Abstract 73P.

44. Hamilton E, Clay TM, Blackwell KL. New perspectives on zoledronic acid in breast cancer: potential augmentation of anticancer immune response. Cancer Invest. 2011;29(8):533-541.

45. Thurston SJ, Zelt SC, Botteman M. Cost-effectiveness of zoledronic acid (ZOL) for the treatment of bone loss in postmenopausal women with early-stage breast cancer receiving aromatase inhibitors in the United States (US). J Clin Oncol. 2010;28(Suppl):Abstract e11007.

46. Winter MC, Holen I, Coleman RE. Exploring the anti-tumour activity of bisphosphonates in early breast cancer. Cancer Treat Rev. 2008; 34(5):453-475.

47. Wu EQ, Xie J, Signorovitch J, Diener M, Sorg R, Namjoshi M. Number needed to treat and treatment cost per fracture avoided with denosumab compared with zoledronic acid in patients with breast cancer with bone metastases [poster]. Presented at: 2011 ASCO Breast Cancer Symposium; September 8-10, 2011; San Francisco, CA. Abstract 151.
48. Candelaria-Quintana D, Dayao ZR, Royce ME. The role of antiresorptive therapies in improving patient care in early and metastatic breast cancer. Breast Cancer Res Treat. 2012;132(2):355-363.

49. Gnant M, Mlineritsch B, Schippinger W, et al; for ABSCG-12 Trial Investigators. Endocrine therapy plus zoledronic acid in premenopausal breast cancer. N Engl J Med. 2009;360(7):679-691.

50. Gnant M, Mlineritsch B, Luschin-Ebengreuth G, et al. Long-term follow-up in ABCSG-12: significantly improved overall survival with adjuvant zoledronic acid in premenopausal patients with hormonereceptor-positive early breast cancer [oral]. Presented at: 2011 CTRCAACR San Antonio Breast Cancer Symposium; December 6-10, 2011; San Antonio, TX. Abstract S1-S2.

51. Meads MB, Hazlehurst LA, Dalton WS. The bone marrow microenvironment as a tumor sanctuary and contributor to drug resistance. Clin Cancer Res. 2008;14(9):2519-2526.

52. Shiozawa Y, Havens AM, Pienta KJ, Taichman RS. The bone marrow niche: habitat to hematopoietic and mesenchymal stem cells, and unwitting host to molecular parasites. Leukemia. 2008;22(5):941-950.

53. Coghlin C, Murray GI. Current and emerging concepts in tumour metastasis. J Pathol. 2010;222(1):1-15.

54. Aft R, Naughton M, Trinkaus K, et al. Effect of zoledronic acid on disseminated tumour cells in women with locally advanced breast cancer: an open label, randomised, phase 2 trial. Lancet Oncol. 2010;11(5):421-428.

55. Lin AY, Park JW, Scott J, et al. Zoledronic acid as adjuvant therapy for women with early stage breast cancer and disseminated tumor cells in bone marrow [abstract]. J Clin Oncol. 2008;26(Suppl):20s. Abstract 559.

56. Rack B, Juckstock J, Genss EM, et al. Effect of zoledronate on persisting isolated tumour cells in patients with early breast cancer. Anticancer Res. 2010;30(5):1807-1813.

57. Solomayer EF, Gebauer G, Hirnle P, et al. Influence of zoledronic acid on disseminated tumor cells (DTC) in primary breast cancer patients [poster]. Presented at: 31st Annual San Antonio Breast Cancer Symposium; December 10-14, 2008; San Antonio, TX. Abstract 2048.

58. Kim MY, Oskarsson T, Acharyya S, et al. Tumor self-seeding by circulating cancer cells. Cell. 2009;139(7):1315-1326.

59. Coleman RE, Marshall H, Cameron D, et al; for AZURE Investigators. Breast-cancer adjuvant therapy with zoledronic acid. $N$ Engl J Med. 2011;365(15):1396-1405.

60. Gnant M, Mlineritsch B, Stoeger H, et al; for Austrian Breast and Colorectal Cancer Study Group, Vienna, Austria. Adjuvant endocrine therapy plus zoledronic acid in premenopausal women with early-stage breast cancer: 62-month follow-up from the ABCSG-12 randomised trial. Lancet Oncol. 2011;12(7):631-641.

61. Hoff AO, Toth BB, Altundag K, et al. Frequency and risk factors associated with osteonecrosis of the jaw in cancer patients treated with intravenous bisphosphonates. J Bone Miner Res. 2008;23(6):826-836.

62. Ripamonti CI, Maniezzo M, Campa T, et al. Decreased occurrence of osteonecrosis of the jaw after implementation of dental preventive measures in solid tumour patients with bone metastases treated with bisphosphonates. The experience of the National Cancer Institute of Milan. Ann Oncol. 2009;20(1):137-145.

63. Badros A, Terpos E, Katodritou E, et al. Natural history of osteonecrosis of the jaw in patients with multiple myeloma. J Clin Oncol. 2008;26(36):5904-5909.

64. Coleman R, Bundred N, de Boer R, et al. Impact of zoledronic acid in postmenopausal women with early breast cancer receiving adjuvant letrozole: Z-FAST, ZO-FAST, and E-ZO-FAST [poster]. Presented at: 32nd Annual San Antonio Breast Cancer Symposium; December 9-13, 2009; San Antonio, TX. Abstract 4082.

65. Barlev A, Song X, Ivanov B, Setty V, Chung K. Payer costs for inpatient treatment of pathologic fracture, surgery to bone, and spinal cord compression among patients with multiple myeloma or bone metastasis secondary to prostate or breast cancer. J Manag Care Pharm. 2010;16(9):693-702.

66. Zhou Z, Redaelli A, Johnell O, Willke RJ, Massimini G. A retrospective analysis of health care costs for bone fractures in women with earlystage breast carcinoma. Cancer. 2004;100(3):507-517. 
International Journal of Women's Health

Dovepress

\section{Publish your work in this journal}

The International Journal of Women's Health is an international, peerreviewed open-access journal publishing original research, reports, reviews and commentaries on all aspects of women's healthcare including gynecology, obstetrics, and breast cancer. Subject areas include: Chronic conditions (migraine headaches, arthritis, osteoporosis);

Endocrine and autoimmune syndromes; Sexual and reproductive health; Psychological and psychosocial conditions. The manuscript management system is completely online and includes a very quick and fair peer-review system. Visit http://www.dovepress.com/ testimonials.php to read real quotes from published authors.

Submit your manuscript here: http://www.dovepress.com/international-journal-of-womens-health-journal 